\title{
Disease investigators - The Laboratory Centre for Disease Control
} NFLUENZA SHIFTS AND DRIFTS. THE DRAMATIC RISE IN Iverotoxigenic $E$ coli, the race for prominence between campylobacter and salmonella, listeria causing meningoencephalitis, prevalence of Alzheimer dementia, and arbovirus infection rates are just a few examples of the many pieces of epidemiological information basic to our ability in Canada to adjust to and confront health problems and risks. How these data are collected, interpreted and used to impact disease is an impressive lesson in teamwork.

From the perspective of public health. Canada has impressive federal-provincial networks such as provincial epidemiologists, provincial laboratories, universities and professional associations working with the Department of Health and Welfare.

Through the National Health and Welfare Act, the federal government has responsibility for carrying out investigations and research into public health, collecting and disseminating public health information and coordinating public health efforts with the provinces. A major component of the Department of Health and Welfare's ability to carry out the disease control aspects of this mandate is the Laboratory Centre for Disease Control (LCDC).

The LCDC is comprised of microbiological laboratories targeted at pathogen groups complemented by epidemiological units of Communicable Diseases, Chronic Diseases and Biostatistics. Its roles are similar to those of the Center for Disease Control in Atlanta, although the scope and approach differ by necessity and orientation.

The LCDC's main functions are:

- Laboratory reference services

- Investigative research both populationbased and in laboratories

- Technology development in laboratories
- Outbreak investigations

- Information dissemination

- Education

The approach most often used by LCDC to achieve these functions is to be the hub of networks of provinces and other institutions or organizations oriented at priority problems and emerging disease threats.

How did the LCDC evolve and how does it work? Decades ago, the Laboratory of Hygiene carried out rational programs targeted at foodborne infection and other diseases. In ensuing years the provinces provided more and more such services themselves, and expertise grew as did the size of programs especially in larger provinces. As this expertise developed and the periphery grew, the role of the federal government began to evolve towards more specific reference work. With the increasing development of epidemiology as a prominent science, the LCDC came into being in the 1970s.

The LCDC continues to evolve and is growing into a proactive investigative tool for emerging diseases, disease trends and risk factors. It plans its role and coordinates activities closely with the provinces and with provincial needs. Intended to be a complementary resource, it is sometimes perceived as a competitor, rather than an ally. This is a misconception which the LCDC is working diligently and tactfully to overcome. Certainly. there is a need to investigate and probe disease outbreaks not only for immediate control but also to define further epidemiology, pathogenesis and other aspects of a particular disease. When a disease is emerging, or its burden on healthcare changing, someone must take the first steps to provide tools for detection, definition and control. To be that proactive, leading investigator is the mission of the LCDC.

In this period of growth and adjustment for the 
centre, several key initiatives are taking place. The centre has been organizationally restructured to allow for programs along logical, disease-oriented lines such as an enterics program. An active recruitment program is attracting epidemiologists, microbiologists and statisticians with competitive academic qualifications and impressive track records. Programs are being rekindled to be proactive and scientifically precise. Finally, resources are now being attracted to allow continued growth.

The LCDC is involved heavily in academic training in applied epidemiology and public health microbiology at the postgraduate and postdoctoral/post fellowship levels. Staff have academic cross appointments at numerous universities and publish at competitive levels in peer review journals. The LCDC's publication Canada Disease Weekly Report is indexed in MEDLINE and ex- cerpts appear in The Canadian Medical Association Journal and international publications such as the World Health Organization's Epidemiological Bulletin. Applications for scientific positions are increasing as is the interest level of the Canadian scientific community.

The country needs a national investigator, a shoe-leather epidemiologist, to be applied at certain times to certain situations. Following the CDC's example, the provinces expect it, and the scientific community assumes it. The growth of the LCDC needs to be nurtured and assisted. The federal setting is not especially limiting or constricting, and builders and innovators can make a difference. The LCDC needs to continue to attract competent, productive scientists to build infectious and chronic disease programs, to innovate in the fertile and cooperative environment of public health we have in Canada. 


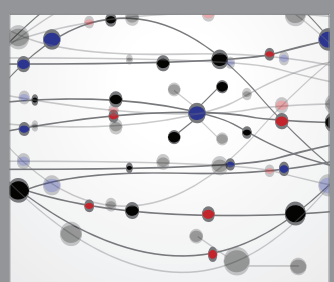

The Scientific World Journal
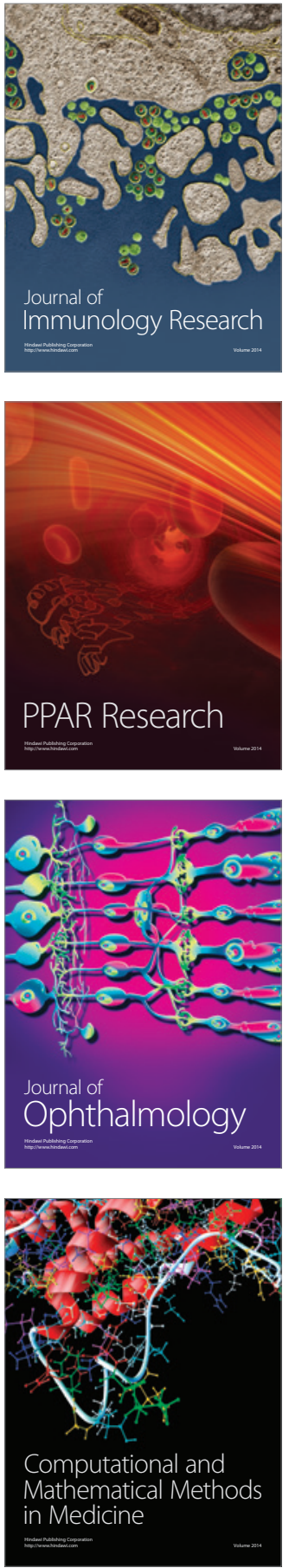

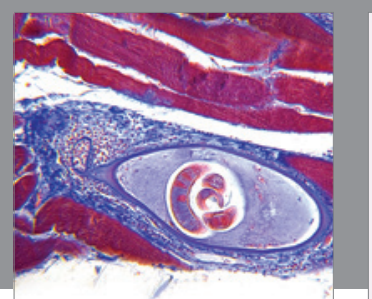

Gastroenterology Research and Practice

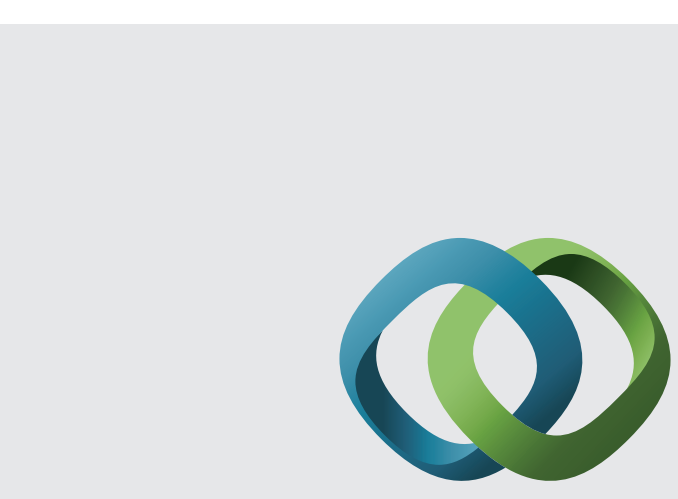

\section{Hindawi}

Submit your manuscripts at

http://www.hindawi.com
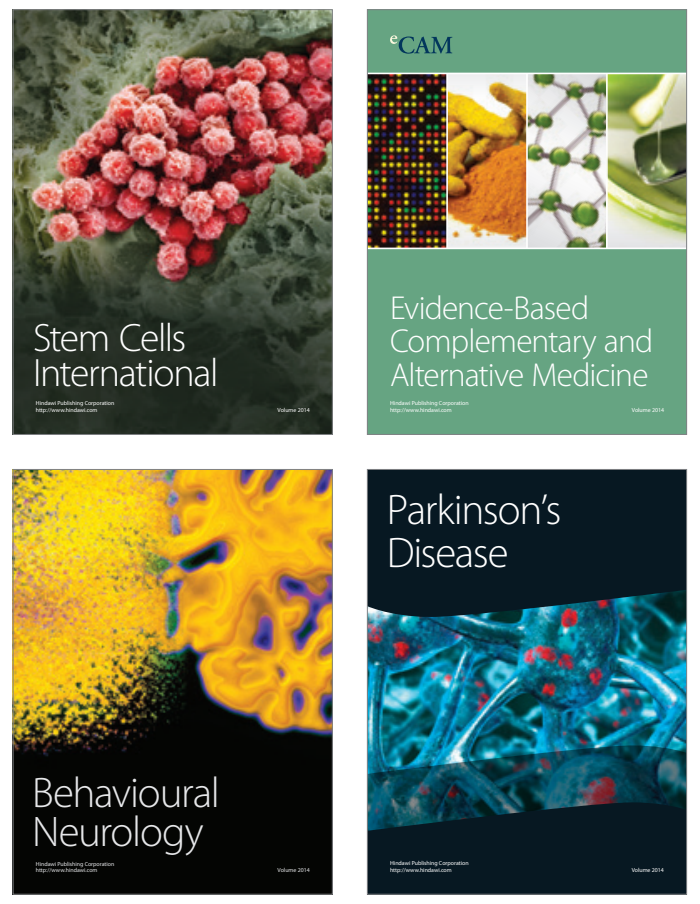
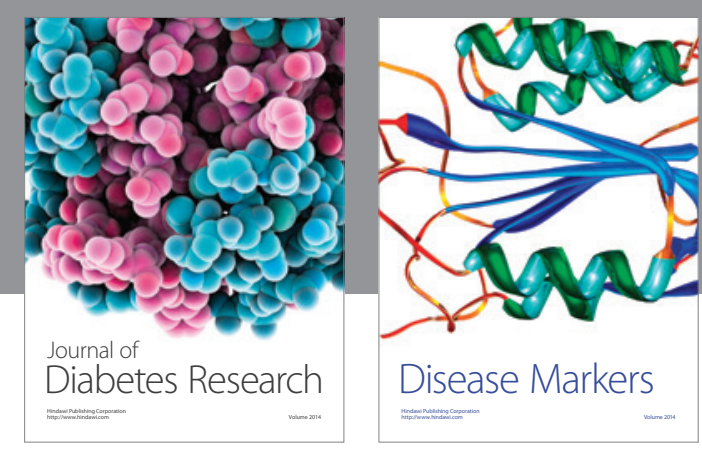

Disease Markers
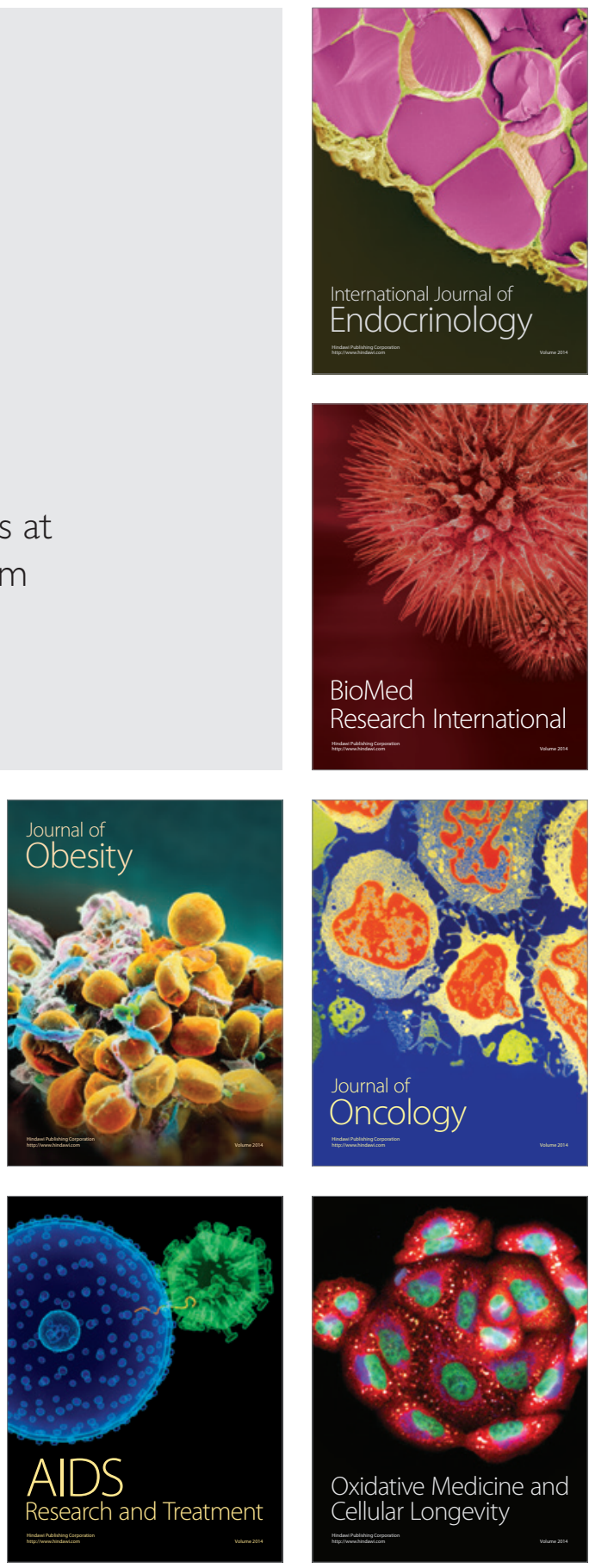